\title{
28 Research Square \\ Sexual and Gender Minority Health Curricula in Health Care Professional Schools
}

\section{Mandi L. Pratt-Chapman ( $\nabla$ mandi@gwu.edu )}

Research article

Keywords: LGBTQI, sexual and gender minority, curricula, implementation

Posted Date: March 23rd, 2020

DOI: https://doi.org/10.21203/rs.2.18264/v2

License: (c) (i) This work is licensed under a Creative Commons Attribution 4.0 International License.

Read Full License

Version of Record: A version of this preprint was published at BMC Medical Education on May 6th, 2020.

See the published version at https://doi.org/10.1186/s12909-020-02045-0. 


\section{Abstract}

Background: Lesbian, gay, bisexual, transgender, queer, and intersex people-inclusively termed "sexual and gender minorities"-have unique health and health care needs that are not being met by most healthcare providers due to lack of training in health care professional schools. The purpose of this qualitative study was to examine implementation factors for advancing sexual and gender minority health professional student curricula in academic settings. Methods: Semi-structured interviews guided by the Consolidated Framework for Implementation Research (CFIR) were conducted with sixteen curricular champions to identify factors relevant to curricular adoption, integration, and sustainment. Themes were coded using a hybrid of deductive and inductive approaches and reported using major CFIR domains. Results: Facilitators supporting implementation of sexual and gender minority health curricula included collaboration among multiple stakeholders, alignment of formal and hidden curricula, fostering an organizational culture that valued inclusion and diversity, engagement with external subject matter experts or faculty with content expertise, and thoughtful and inclusive planning. Conclusion: This study contributes to health care professional education research as well as to implementation science. Facilitators that were identified in this study can be used to increase the adoption, integration, and sustainment of sexual and gender minority health curricula in diverse academic settings.

\section{Introduction}

Lesbian, gay, bisexual, transgender, queer, and intersex people-inclusively termed "sexual and gender minorities" (SGM)-have unique health care needs not being met by most health care providers. ${ }^{1-3}$ Lack of provider competence-including knowledge of and attitudes toward SGM, culturally-affirming behaviors, and clinical management strategies-have a direct impact on SGM patient experiences with health care, healthcare seeking behaviors, and health outcomes.

However, health care professional student curricula focused on SGM content is minimal: Medical students receive a median of five hours, ${ }^{1}$ nursing students a median of 2.12 hours, ${ }^{4}$ and dental students an average of 3.68 hours ${ }^{5}$ of health content specific to SGM populations. Published studies of healthcare professional learning interventions to improve one or more components of clinical competence and/or to moderate student bias against SGM patients in academic healthcare settings are relatively rare. Interventions for pre-graduate students are even fewer.

Given the relative newness of the introduction of SGM curricular content to health care professional student education, this study aimed to examine implementation factors that advanced SGM health curricular adoption, integration, and sustainment in academic settings for medical, nursing, and pharmacy students. The focus on implementation is intended to inform efforts of future SGM curricular champions in diverse settings.

\section{Methods}


A literature review was conducted to identify SGM curricular interventions published within the last five years. Eligible studies were clustered by institution (see Table 1). Champions for SGM curricular change from 21 institutions in the U.S. and U.K. were invited for interview. A total of 16 participants agreed to be interviewed from January to February 2019. Qualitative data were transcribed using Rev.com (San Francisco, CA) and coded by the author using NVivo 12 software by QSR International. No incentives were provided to interviewees.

\section{Instrumentation}

The interview guide was structured based on constructs from the Consolidated Framework for Implementation Research (CFIR) ${ }^{6}$ (See Figure). The CFIR was created as an overarching typology to consolidate the overlapping implementation theories that arose in recent years in the attempt to more quickly expedite efficacious interventions into effective health care practice. The semi-structured interview protocol included questions about the major domains of the CFIR, including individual characteristics, intervention characteristics, inner setting, process, and outers setting (See Supplemental Material).

\section{Procedures}

The following criteria were used to establish trustworthiness of qualitative findings. Credibility was established through feedback by senior faculty[1] on research design, instrumentation, and coding approach. Transferability of findings was established through thick description and transparency of data collection protocols. ${ }^{7}$ The author documented self-reflexive memos throughout interviewing and data analysis. Process documentation contributed to confirmability through senior faculty auditing. Member checking ${ }^{7}$ was used by sharing thematic codes and examples of themes with interviewees and encouraging participant feedback on the accuracy of analysis prior to data reporting. Furthermore, a colleague with expertise in SGM curricular change in two academic settings reviewed the findings to confirm transferability.

Anonymity and Confidentiality. Interviewees were recruited based on authorship of a published learning intervention (see Table 1). Themes and quotations do not identify the interviewee nor the institution where the intervention was implemented to maintain anonymity. However, given the small number of institutions who have led curricular change in this area, it is possible that information could be suggestive of particular institutions.

Data management. Recordings of WebEx videos and audio files were stored in a Box folder on secure servers. Qualitative data were transcribed by uploading to Rev.com (San Francisco, CA), a secure platform that stores and transmits files using TLS 1.2 encryption and a 128-bit AES key (Myers, 2107). Transcripts were de-identified and stored in a separate Box folder available only to the author and mentoring faculty. ${ }^{*}$ Transcripts were uploaded into NVivo 12 for coding and analysis.

\section{Data analysis}


The author conducted open, single coding using a mixed deductive-inductive process, beginning with examination of CFIR domains. Participants were also asked about recommendations for the field and coded as "Recommendations for Future Work." Child and grand-child nodes were inductively coded.

[1] The author was a doctoral candidate and has now graduated. The senior faculty member was Chair of the author's dissertation committee.

\section{Results}

\section{Individual Characteristics: Empowered, motivated institutional champions are key}

Individual characteristics that emerged were focused on the level of empowerment felt by interviewees in changing SGM curriculum in their academic setting. Themes included feeling empowered or motivated versus feeling disaffected. The themes of motivation and empowerment were common across nearly all interventions - motivations varied, but institutional champions with passion for SGM health were critical for success. A few interviewees mentioned feeling disaffected, either by the hierarchy of medicine that can intimidate students when noticing non-affirming care modeled by senior faculty or from burnout after years of feeling unsupported by administrators. Those who felt empowered described efforts to lead change at various levels, including at the national level.

Empowerment. Some interventions were student led, and some were faculty led, but for most learning interventions both faculty and student engagement were important. One student interviewee who spearheaded SGM curriculum in an urban setting said, "Honestly, I felt very shielded from institutional barriers, because of the faculty, because of our faculty sponsors." In other settings, faculty reported being in a position to either directly change curricula within a course or feeling empowered by administrators to enact broader curricular change. In some cases, the champion was a high-level administrator. One course director said,

I called it a content change. I said that curriculum would just be the general endocrine curriculum, but I was adding a little bit of content to what the general endocrine curriculum should now be. (laughs) So the point is, I didn't ask anybody and so that helped.

Another faculty had authority over the entire curriculum for the medical school:

I led the efforts to create the competencies around cultural competence that we use...Now... I'm the acting associate vice-chancellor for diversity and inclusion so I oversee the full gamut of diversity efforts.

For most successful interventions, a combination of student and faculty engagement was key.

Regardless of whether students or faculty initiated curricular change, successful implementation relied on at least one strong institutional champion. One doctor, who initiated curricular change when she was a medical student said: 
I was in my first year and one of my friends was in a more senior year, and she'd just done a teaching week that was focused around kind of disability and diversity and things like that. And then she said, "But it was really weird, because there was nothing on...LGBT material or the demographic at all." And I kinda said, "Well, that's a bit stupid. Maybe we should try and do something about it."

The student noted the importance of having a strong faculty champion to support her as well as institutional supports-such as time and lecture space--to deliver curricular content to other students.

Motivation. Reasons for motivation varied, but most institutional champions reported being strongly motivated. Several curricular champions noted the dearth of content in the existing curricula and wanted to remedy that gap: "I graduated in $2011 \ldots$ so somewhat recently. But my clinical and pre-clinical education was: 'HIV happens more frequently to gay men. The end."' Others were motivated by personal experiences of discrimination or hearing of others' experiences: "I think part of it just comes from lived experience as a gay person." One ally said after being SafeZone trained and hosting a transgender panel for her students, "I was just astounded. And, I thought, before that point, that I was a pretty like, liberal, cool person. Two of my best friends were gay, and I thought, 'Oh, yeah, I know all this.'... But, I never had the opportunity to really think about what it was like to be them, and to live in, you know, our culture." Other interviewees were motivated by a strong belief in accessibility health care for all: "[l]t doesn't matter what your personal belief system is related to transgender health or care. If you believe that people should be transgender or don't believe that they should be is irrelevant. Their human health is what's relevant. So we have people that can't access healthcare based on their provider bias." One respondent passionately spoke about discovering the biological foundation of gender dysphoria. His epiphany came from learning about failed genital surgeries on intersex children. He used this discovery to introduce the concept of biology in gender identity to students while sensitizing future physicians on the needs of transgender patients.

Only a few interviewees mentioned feeling disaffected. A few faculty champions mentioned feeling unsure how higher-level administrators would react to the introduction of SGM content in their course. One student champion said, "It's really hard. I've said stuff and it's backfired and I've not said stuff and felt terrible afterwards that I didn't say anything and...I consider myself a little bit above average with this particular topic in medicine." While not unique to SGM issues, the hierarchy in medical education intimidated some learners to speak up. A tenured faculty who felt no support or incentive to invest in SGM curricular change reported, "I've kind of given up...it doesn't seem like these types of trainings are effective ...so I don't try to guilt people out, but I just try to, make people aware of how vulnerable this population is."

National leadership. A few curricular champions worked to effect change at a national or international level beyond their institution. One faculty member used his position of authority to influence the standard of care for intersex patients by serving on a WPATH committee: "My goal, we'll see if I succeed, my goal and this is at WPATH--where you think you'd have a friendly crowd-forget the pediatric crowd, my goal is to be able to have them say out loud that 'when feasible,' just put it at that because they don't have any 
data so they can't say in this situation that situation or the other situation, just simply 'when feasible' surgery should be delayed." It is important to note that WPATH guidelines are for transgender patients, not intersex patients; however, there is an intersex working group in WPATH specific to transgender intersex people. This faculty leader leveraged his reputation as a transgender health expert to effect change for intersex patient standards of care within WPATH. Other faculty mentioned serving on national committees to effect change.

\section{Intervention Characteristics}

Interventions showed wide variations in leadership and topics covered. Expertise to deliver content was a major theme that affected intervention characteristics. Sustainability was influenced by the degree to which the curriculum depended on one versus many collaborating stakeholders.

Wide variation. Interventions were diverse, ranging from one-off, elective interventions to complete curriculum overhaul. The level of integration also varied widely from student-led projects without sustainability to course directors adopting specific content for their course to curricular leaders requiring students to demonstrate competencies in SGM health to graduate from medical school. Faculty in a school that revised 50 hours of highly-integrated curricular content emphasized the importance of delivering content at relevant, teachable moments:

If we're talking about hormonal medication when we...teach about hormonal medications, they're used to treat prostate cancer, they're used to treat breast cancer, they're used to prevent... conception, and they're used for multiple other purposes, and they're also used for gender affirming care in transgender patients. So we would just integrate to that content. When we taught the sexual history, we just integrated more affirmative, inclusive language, and kind of broadening what you ask about, and what specific questions you might ask. So we didn't have a, oh, "and once you realize your patient's gay, you need to do these sort of things." It was more...Like kind of approaching the personhood and then things would unfold a little bit more naturally. When we...teach about healthcare disparities, talking about specifically the healthcare disparities for this population, and where their roots are. We talked about psychiatric treatment, and counseling specifically, teaching that, conversion therapy is contraindicated...carries with it a higher risk of suicide. Were we teaching this stuff anyway without being inclusive, affirmative, or getting us closer to these goals.

In contrast, a student who led an elective intervention voiced disappointment that "I kind of had classmates feel like this was more cosmetic, elective stuff that I was teaching, or trying to teach." Another student said she felt the content would be taken more seriously if students were tested: "I feel like you actually have to test people on the content 'cause mine was just sort of, it was a quiz but it wasn't actually part of the grade. And I think people take things a little more seriously when you actually grade them."

Content for learning interventions included basic terminology, bias training, mental health considerations, social determinants of health, and transgender care considerations. Pedagogical approaches included 
learner reflection, community member panels, faculty self-disclosure, and didactic lecture. Almost universally, intersex content was not discussed at all. One interviewee said, "No, we don't talk a lot about intersex and what does that mean and um, yeah, we just don't." The two exceptions to not addressing intersex content was having students watch the film Intersexion and having a legal discussion as part of a breakout session for an elective all-day student-led forum. One respondent indicated a brief mention of the definition of intersex in her four-lecture learning intervention.

A major theme was the need to increase student exposure to SGM given broadly unexamined bias and lack of basic knowledge. One interviewee mentioned that he felt successful if students took away the basic fact that sexual orientation and gender identity are different constructs: "I set realistic, low bars for myself. So my goal for the first two lectures of the transgender health elective, [was]: sexual orientation and gender identity are different. Like that was my goal. We talked about other things as well, but sometimes students need to hear that multiple times." To address bias, many interviewees emphasized the importance of exposure to the SGM community via patient panels, "out" faculty, or experiential clinical rotations. Several interviewees emphasized the importance of narratives from the SGM community to combat bias. One pharmacy faculty said:

It's much harder to you know...say, I do not support and I will never, and then all of a sudden somebody comes out and says, "Yeah, well, my daughter, my son, my family member..." And now all of a sudden they've done a 180 in their personal position...I think it's...easier to hold a bias on a concept. It's harder when somebody is in front of you and they're telling you their life story and they're explaining the challenges that they face and how pharmacists either helped or hurt in their personal journey. I think it's much harder to walk out of that experience and say I wasn't touched.

Another interviewee described her experience coordinating her first transgender panel for students: "But when you see them actually engaging and talking to the students, that's where it was like, 'This is what students need.' They need to understand that these are individuals. To have that really open discussion with them. And it was remarkable. It was remarkable." Many interviewees emphasized the need to counter explicit or implicit bias and the impact a small amount of exposure-such as a community panel-could yield.

Content expertise. Another major theme was how the availability or lack of content expertise shaped the curriculum. Content that was included tended to be guided by existing faculty expertise or external expertise-either from within the community, such as patient narratives or LGBT nonprofit organizationsor from visiting faculty from other institutions. One interviewee said they started with "content experts that we have available." Another interviewee described early institutional efforts to broadly train faculty through external expertise: "[W]e hosted a one-day faculty development event that brought in [experts] from their respective institutions as national leaders in LGBT care and medical education related to LGBT care to develop all of our faculty that we felt would have a role in- in adapting our education and refining our education offerings to students." Other faculty emphasized reliance on their local LGBT community organization: "[B]ecause I was so new to this and, initially the very first time I had just done a Safe Zone 
training, it opened my eyes. And, I asked the Gay Alliance. I kinda followed their lead about what should be incorporated."

Several interviewees mentioned that SGM-related health curriculum was not offered by existing faculty, because they were never trained in SGM health and did not feel they had appropriate expertise. One person said colleagues feel like, "I'm not a content expert, this isn't something I know a lot about and I don't know where to go to find the information so it's just easier if I don't teach it." Another interviewee agreed: "Faculty may want to do it but they don't feel comfortable doing it. They don't feel comfortable teaching it. So part of it is, you know, the curriculum, the cultural competence folks, we need to...do our homework in terms of identifying and securing the resources, the content expertise."

Sustainability. For sustainability, themes of diverse stakeholder engagement and appropriate resource supports were strong. One person mentioned the ongoing effort required for this work: "And so you always need to be reengaging and engaging new people into what you're doing or all of that hard work is just going to go by the wayside as soon as those couple of people are gone." Level of institutional resource support-through protected faculty and/or staff time was noted as important. These sustainability factors are detailed further in the "Inner Setting" and "Process" sections below.

\section{Inner Setting: Institutional support bolsters success}

Two intertwined themes emerged as most critical to the inner setting context, or the academic context into which the SGM curriculum was introduced. Culture was an important factor, which included organizational values, organizational readiness, and the "hidden curriculum"--or the ways in which clinical practice and faculty behaviors reinforced or contradicted what was taught in the classroom. Institutional commitment, came in the form of leadership support, financial resources, protected faculty time, and staff support.

Culture. Cultural values emerged as a vital factor for inner context. The reasons for supporting SGM curricula varied, but alignment with the culture of the institution was helpful. A few interviewees reported institutional cultures that valued change leadership: "You know, there was just such enthusiasm from, you know, our dean, CEO, president, all the way on down, to really think about how we could be a leader and shape the national conversation and space." Several interviewees mentioned that their institution was mission-driven, so serving "neglected populations" aligned with the institutional mission. Several others indicated a strong culture of inclusion that supported diversity initiatives. Culture was linked to organizational readiness. For those institutions that valued leadership change and inclusivity, interviewees noted that strongly supportive leadership: "[If he hesitated or hadn't given me the top cover to really kind of push on this and be very visible, then I don't know if we would have moved forward."

Culture was noted in mentions of the "hidden curriculum." One student leader said, "I mean in general, so much of med school learning is the hidden curriculum. How you model it, what words you use to describe certain patients, I mean that extends to so many things beyond sexual gender minority status. And it's really variable depending on sites as well." In contrast to environments where the hidden curriculum was 
in tension with the formal curriculum, interviewees where curriculum was aligned reported a number of synergistic activities that occurred in conjunction with or following curricular change. These included direct outreach on campus to raise awareness among diverse stakeholders, new clinical services or environmental changes to make clinics more affirming, and faculty recruitment that reinforced an SGMaffirming environment. One faculty member mentioned that in response to patient complaints, their affiliated hospital started a concierge service specifically for SGM patients. Another mentioned a mentorship program that matched incoming SGM medical students with "out" faculty. The most common change that occurred to align new SGM formal curriculum with the hidden curriculum was new or expanded opportunities for students to have relevant clinical rotations. An interviewee that spearheaded a highly integrated SGM curriculum approach said, the curriculum was reinforced by "clinical programs that have now developed in support of our sexual, gender, and minority patients. Which, again, wasn't anywhere on our radar, but has been very synergistic and important in allowing the educational component to work."

Institutional commitment. A theme closely related to culture was institutional commitment. Commitment came in different forms, including leadership support, money, protected faculty time, and staff support. Faculty indicated that leadership support was critical: "We've had good leadership from the top...that has invested....and that's been a key ingredient." In contrast, a disaffected faculty member that did not receive support said, "If we're really gonna be serious about this we have to think about ways that have some kind of financial and institutional support and...I can't think of the word, but you know [how] it can get to be kind of put into the brick and mortar a bit, you know." The same person was frustrated by the expectation of volunteerism: "I think the biggest issue for me really is, it just seems like what institutions want is somebody at the institution to take this on and to...do it as an add-on. So l've heard that from a lot of people and I've experienced that myself." In contrast, institutions that resourced staff support attributed success to dedicated staff: "The investment the institution made in the LGBT center, I mean, this work would not have moved forward without having someone [who] is a passionate advocate and great at getting people together." Protected faculty time was another ingredient for success, particularly for more system-wide curricular interventions: "I got time carved out to work on this and then when I became a dean and and associate vice-chancellor, I carved out faculty time to work on curriculum."

\section{Process: Planning and ongoing engagement are needed}

In terms of the process of introducing SGM curriculum in academic health professional settings, three major themes emerged: the importance of strategically planning, consideration of contingencies (facilitators or barriers to curriculum enhancement), and responding to opposing views.

Strategic planning. Strategic planning included needs assessment, broad stakeholder engagement, and intentionally planning sequence and content of curriculum to optimize learning. Needs assessments ranged from broad, survey-based assessments to research mining SGM community member perspectives to informal conversations with peers. One student curriculum champion said, "I figured there's no point in just starting something if, with stuff that I think is important, if other people are like, 'We already know 
this, but we really wanted to hear about-.' So I just tried to ask around and to see what people knew about and what they didn't know about."

Engagement of stakeholders ranged from informal conversations with leadership and students to entire retreats to map out new curricula. One administrative leader who took the retreat approach said:

So what we did was we invited people from various stakeholder groups... we identified folks who were curricular gatekeepers and these were the course directors, course instructors. We had people who were LGBTQ...And they would serve as our content experts and then we had in our cultural competence committee, we had the facilitators, people who could bridge because they were familiar with the curriculum but they were also familiar with cultural competence and LGBTQ health competencies....And then we had...students or residents that could sort of give the end-user or the consumer perspective of this process.

Other interviewees leveraged standing committees or created committees to focus on curricular change. One interviewee mentioned involving community members in their advisory committee: "about eight community members, that met monthly for about a year, and reviewed all the curriculum content and offered feedback...[T]hat it was, ya know, nothing about us, without us, kind of thing." Overall, some mix of student, faculty, and administrator engagement were consistently noted as key to successful, sustainable curricula.

Key lessons learned included: 1) making SGM curriculum implementation the purview of more than a few people; 2) starting with what you have; and 3) showing the necessity for the content. See Table 2 for major lessons learned and illustrative quotations.

Contingencies. In terms of potential barriers or facilitators to implementing SGM curricula, the revision process was the most frequently cited contingency. Several people mentioned how impacted medical school curricula are, particularly with a condensed structure. Time constraints were mentioned in tandem with potential opportunities and challenges of curricular revision. One interviewee who had worked hard on integrating SGM curricula said, "[W]e've subsequently gone through some real curricular revisions... where, frankly, a lot of that content and initial work was lost, because we went from a very traditional two years of basic science followed by two years of clinical rotations to a 13-month basic science integrated curriculum followed by core rotations in year two." In contrast, others mentioned curricular revision as an opportunity:

We were undergoing curriculum renewal anyway. So, it was a good time to take advantage of that opportunity and - to kind of focus changes into all the other changes that were happening anyway. So, I mean...that's actually part of our culture here, too...Faculty are really not used to having anything be the same from one year to the next. Like...They don't have that expectation, they don't tend to roll in with the expectation, "I'm just going to get up and use my slides from last year." ...So, it made making changes a little bit easier. Our committees are not entrenched for that reason. They're just like, "Oh, is there more 
change? Okay, I thought I was full of change, I guess we'll have another helping." So, um, that part was pretty easy.

In sum, curriculum revision is a time when new content can be strategically incorporated, but content that has been recently revised may not be retained if there is not broad buy-in for the importance of the content. Organizational culture that expects ongoing change was noted as a facilitator. In contrast, another interviewee described his institutional culture as "trying to stay with the tried and true... it is very much an old school culture." This more inert culture was noted as a barrier to curricular change.

Responding to opposition. A few interviewees offered insights into responding to opposing views. Two major oppositions were highlighted: time constraints and conservative pushback. In response to time constraints, one interviewee noted:

We need to do a better job of intentionality. You know, and to move away from this old model of, I just spew every piece of knowledge that I have versus, what do they really need to know, what can they look up later, what's available in the database? You know, what's going to give them the foundation to be successful and I see that an awful lot in kind of, our curriculum. That it's too jam-packed and the students are too stressed to even think about adding something else in. But if we were more, if we removed redundancies and were more intentional there would be space for things that are important and quite frankly, I feel like a curriculum should be a living organism.

In terms of conservative pushback, another interviewee said,

Especially because we're down here in the Bible belt...there's some very strong opinions... There's 110,000 transgender people that live in [city] alone, you know, we're third in the country. Just giving them the facts of the data, as to the importance of what we're doing. It's human health. It has nothing to do with gender bias, has nothing to do with sexual orientation. It's related to human health. And if we all believe that all humans should have access to health, then we should all believe that this population should be able to feel comfortable getting the care they need.

In sum, institutions that integrated curricula at various levels emphasized the importance of assessing learner needs, engaging a variety of stakeholders, and responding to negative pushback. Those who integrated more systems-level curricular change also emphasized the importance of leadership and thoughtful planning to layer and diversify SGM learning opportunities over the four-year medical school experience.

\section{Outer Setting: The Larger Context}

Outer setting was the CFIR domain that seemed least important to successful implementation of SGM curriculum change. The broader context outside of the academic setting shaped curricular content and conversations in class, but were reported as less important for actual implementation than other factors. 
External guidance. External guidance from credible sources and socio-political context were noted as having some effect on curriculum. For external credible resources, some interviewees that were early champions in the 2000s and early 2010 s indicated lack of any real guidance from health care professional organizations, guideline bodies, or the research literature. The most cited guidance, by far, was the AAMC's 2014 report, Implementing Curricular and Institutional Climate Changes to Improve Health Care for Individuals who are LGBT, Gender Nonconforming, or Born with DSD: A resource for medical educators. ${ }^{8}$ Faculty said, "'those are really our marching orders. I mean, we work from those competencies, that's how we diagrammed out a whole curriculum. What would go where, what the subcompetencies or learning objectives would be, what the assessments would be." Another faculty member mentioned institutional pride in achieving and maintaining leadership status in The Human Rights Campaign Healthcare Equality Index (2007). Several interviewees mentioned how useful the Fenway Guide to Lesbian, Gay, Bisexual and Transgender Health ${ }^{9}$ or Fenway Institute online resources were. Lambda Legal's 2010 report When Health Care Isn't Caring ${ }^{10}$ was described as "groundbreaking because it was one of the few studies that really looked at LGBTQ health disparities in a comprehensive way." The Institute of Medicine 2011 report The Health of Lesbian, Gay, Bisexual, and Transgender People: Building a Foundation for Better Understanding ${ }^{11}$ was described as a "game changer."

Socio-political context. Considering sociopolitical context, a major barrier cited was the history of medicine, which has historically pathologized homosexuality:

[L]ooking at actually we as physicians, how are we contributing to that problem? And so do we have offices that are LGBT friendly? Is our staff being appropriate? And then looking at, how medicine used to say that, you know, being gay, lesbian, bisexual was a mental disorder. We didn't really help the problem. Fortunately, that's gone away, but there are still some physicians and staff who think that people like myself are an anomaly or like we need to be handled or whatever. Or they don't wanna see us. Those kind of things.

Notably, intersex status is still pathologized. A faculty interviewee noted:

We allow parents to do pretty nasty stuff to their kids if you think about it. They can brainwash them in all sorts of kooky ways (laughs) and then you're just dependent on your parents' bad choices, independent of anything, even if they're totally reasonable. So the point is kids are pretty vulnerable and we as a society, that's a value that we have, that parents are high priority.

Other examples of regional and national events were cited as socio-political facilitators or barriers to the culture change needed to create more SGM-affirming and prepared clinicians. At the state-level, faculty mentioned the real risks associated with disaffirming legal policies:

You know, like for example the [state] tried to pass a bathroom bill law in the last legislative session in 2017, and which thankfully did not go through. But, as a part of that, locally one of our equality organizations here in the state saw a significant spike in their...suicide crisis hotline from young people as the discussion on that bill was going through. 
Another faculty reported that although her institution felt ready for curricular change, backlash from the religious community was not planned for: "So I think saying you're ready and...then realizing, oh wow, the community is pulsing on this." In contrast, greater community awareness at a national level was noted as a facilitator for dialogue among students and faculty:

There's a lot more recognition and awareness... whether it's Caitlyn Jenner or the transgender ban in the military, things that have been very, very visible...have shaped...the national dialogue...[W]e obviously live in a society that continues to evolve.

Finally, at an administrative level, changes to insurance were noted as a positive change:

[T] he changes in insurance as well has been helpful... gender reassignment, surgery [and] hormone treatment is covered by insurance...[I]t gives us an impetus that, you know, if insurances are covering this and we want to be the best, um, in patient care, then we need to know about this.

Insurance reimbursement was also noted as potential leverage for obtaining higher -evel buy-in given emerging market opportunities.

\section{Recommendations for Future Work}

In addition to examining implementation constructs, insights on where the field of SGM health education and research should go next were sought to help inform future efforts. Two major themes emerged for future directions: inadequate evaluation tools and the need to incentivize inclusion of SGM curricula. Strategies for inclusion of curricula were also offered.

Need for evaluation. The strongest theme that emerged when asked about what the field needs going forward was more robust evaluation tools and approaches. Universally, interviewees were unhappy with existing evaluation options in the literature, and many interviewees had plans to improve evaluation within their own settings. Faculty said, "We've...had some...conversations about whether or not it'd be possible to add in an OSCE, which is ask the skills that people have learned, or at least a component of it." Another person noted the need for "having a tool of assessing how good the teaching is" and to see if people actually retain it for longer than half an hour after they go out of the session." Another faculty said:

So, we've done the content integration, which is great...we think that our students are learning, but we don't have any milestones in this space that are baked into our assessment tools that allow us to really know and have confidence that our students are graduating with these competencies. And, so that's something that, you know, is on our radar, but we just haven't gotten there.

Other interviewees noted that better evaluation tools were not only needed to assess student skills but for research. 
Incentivizing SGM health in curricula. Several interviewees noted the importance of incentivizing inclusion of SGM content in curricula. Diverse approaches were suggested. One administrator suggested embedding SGM competence into graduation competencies: "Once you embed it in the graduation competencies, the licensing body that we call ... the Liaison Committee on Medical Education, they accredit medical schools and they hold you to achieving your graduation competencies." Another suggestion was to leverage the medical school graduation survey:" So every medical student who's graduating is asked to take a survey of their medical school experience... It has a question on gender bias...mistreatment associated with your gender or sexual orientation. It has questions on your comfort level treating people from culturally diverse backgrounds... If your school doesn't do well in that, then, that's an indication that, you know... you need to fix it because if you don't, you're going to be in trouble by the accrediting body." Another faculty suggested leveraging the market competition: "If you can say, 'Oh, this institution down the street has this awesome curriculum, but we don't. That's a problem."' Finally, developing off-the-shelf resources was noted as a need for the field: "We need to create things that are off the shelf. I want to talk about transgender healthcare okay? Do you want to talk about just LGBTQ basics? Perfect. Here's the module. Do you want to talk about hormone replacement therapy? Great. Here's the module. Do you want to talk about in LGBTQ patients, substance abuse and depression? Here's where you can go or here are the resources."

Strategies for curricular inclusion included exploration of shared values, strategic alignment of curricula and intentional exposure of students to SGM people (see Table 3).

\section{Discussion}

Findings from this study support past research that has demonstrated the importance of collaboration in curricular change through stakeholder engagement ${ }^{12}$ and the impact of aligning formal and hidden curricula. ${ }^{13-16}$ Collaboration was reported to bolster curricular integration and sustainability of SGM curricula. Institutions that had organizational cultures that valued inclusion and diversity as well as institutional support were more likely to have leaders that provided resources to SGM curricular champions and more likely to build synergistic initiatives to further align the curriculum to support SGMaffirming care.

Content expertise emerged as critical to what and how SGM content was covered. Content expertise was addressed in a variety of ways-either starting with faculty who felt like experts, building faculty capacity through guidance from external experts, or leveraging expertise from community organizations. Content expertise as a key ingredient to SGM curricular success reinforces results of prior studies. ${ }^{17}$ Additional contributions from this study include the importance of thoughtful planning to build faculty competence in a new topic area to make curricula less vulnerable if one person leaves.

Overall, this study provides support for implementation theory in the context of health care professional pre-graduate education SGM curricular change. In alignment with the "Recipe for successful change" offered by Ambrose the following essential ingredients proved critical for organizational change: vision, 
skills, incentive, resources, and an action plan. ${ }^{18}$ Vision from institutional champions to lead change efforts emerged as foundational for SGM curricular change. Content expertise (skills) needed to be identified or developed. In Ambrose's model, lack of incentives leads to gradual change: this theoretical assumption aligns with the recommendation from interviewees that incentives are needed to expedite SGM curricular change going forward. Resources included institutional support, usually in the form of protected faculty or staff time. Finally, needs assessment and strategic planning align with Ambrose's call for an action plan for change. Support for Ambrose's theory for organizational change provides important data for future researchers who wish to implement systems-level, organizational changes.

\section{Limitations and Strengths}

The major limitation of this study was singular coding of the data, resulting from institutional requirements for an independent project as part of the author's dissertation. In addition, qualitative findings are inherently subjective. Interviewees occupy a subjective position and are likely to be influenced by social desirability bias. Examination of both facilitators and barriers and assurance of anonymity intended to minimize these risks. A strength of this study is its use of implementation theory. This is the first known study to systematically examine contextual factors associated with SGM curricular implementation in pre-graduate health care professional academic settings.

\section{Conclusion}

Few institutions have begun to incorporate curricular change to address the gap in medical, nursing, and pharmacy student learning about SGM health. Findings from this study provide unique insights and clear strategies to aid in the adoption, integration, and sustainment of SGM health curricula into diverse academic settings.

\section{List Of Abbreviations}

CFIR Consolidated Framework for Implementation Science

GW The George Washington University

LGBTQI Lesbian, gay, bisexual, transgender, queer and intersex

SGM Sexual and Gender Minority/Minorities

\section{Declarations}

\section{Ethics approval and consent to participate}

This study was determined to be exempt from full IRB review by the George Washington University IRB (\#180842). Participants were provided with an information sheet describing the purpose of the study, what would be required as a participant, potential risks, and who to contact with questions. The 
information sheet indicated that willingness to participate would be implied if the person agreed to be interviewed. The IRB determination included documentation of this process of implied consent.

\section{Consent to publish}

The results reported in this article were reported in a substantially different form as part of a mixed methods dissertation published in Health Sciences Research Commons available at https://hsrc.himmelfarb.gwu.edu/smhs_crl_dissertations/1/. The copyright was retained by the author who consents to publication in this journal under the open access option. Results were also reported in a poster entitled "Getting sexual and gender minority health 'into the brick and mortar': Results from a mixed methods implementation study" for the Academy Health $12^{\text {th }}$ Annual Conference on the Science of Dissemination and Implementation in Arlington, VA on December 5, 2019.

\section{Availability of data and materials}

Blinded transcripts of interviews can be provided by contacting the corresponding author.

\section{Competing interests}

The author declares no competing interests

\section{Funding}

No funding was provided for this study.

\section{Authors' contribution}

MPC conceptualized the study, collected and analyzed data, wrote the manuscript, and approved the final submission.

\section{Acknowledgments}

The author would like to thank all of the interview participants whose knowledge and experience made this study possible. In addition, the author acknowledges Leslie Davidson, PhD, Chair of the Department of Clinical Research and Leadership at the George Washington University School of Medicine and Health Sciences for serving as Chair of her dissertation committee and for providing qualitative expertise. She would also like to thank her dissertation committee members Brandi A Weiss, PhD and Jennifer Potter, $\mathrm{MD}$ and her dissertation readers Markus Bidell, PhD and Lawrence Deyton, MD. Finally, thank you to Kristen Eckstrand, MD, PhD for serving as a reviewer of the study to ensure transferability.

\section{References}

1. Obedin-Maliver J, Goldsmith ES, Stewart L, et al. Lesbian, gay, bisexual, and transgender-related content in undergraduate medical education. JAMA. 2011;306(9):971-977. 
2. Dowshen N, Gilbert K, Feiler A, Lee S. Transgender health education impact on medical student knowledge, skills and attitudes. J of Adolesc Health. 2013;52(2):S35.

3. McPhail D, Rountree-James M, Whetter I. Addressing gaps in physician knowledge regarding transgender health and healthcare through medical education. Can Med Educ J. 2016;7(2):e70-e78.

4. Lim FA, Johnson M, Eliason M. A national survey of faculty knowledge, experience, and readiness for teaching lesbian, gay, bisexual and transgender health in baccalaureate nursing program. Nurs Educ Perspect. 2015;36(4):144-152.

5. Hillenburg KL, Murdoch-Kinch CA., Kinney JS., Temple H., Inglehart MR. LGBT coverage in U.S. dental schools and dental hygiene programs: Results of a national survey, J Dent, 2016;.80(2):440-49.

6. Damschroder L, Aron DC, Keith RE, et al. Fostering implementation of health services research findings into practice: a consolidated framework for advancing implementation science. Implement Sci. 2009;4(50). doi:10.1186/1748-5908-4-50

7. Lincoln YS, Guba, EG. The Sage handbook of qualitative research. Thousand Oaks, CA: Sage Publications, Ltd. 2005.

8. Hollenbach AD, Eckstrand KL, Dreger A, eds. Implementing Curricular and Institutional Climate Changes to Improve Health Care for Individuals Who Are LGBT, Gender Nonconforming, or Born with DSD: A Resource for Medical Educators. Washington, DC: Association of American Medical Colleges, 2014. 280 p.

9. Makadon HJ, Mayer KH, Potter J, Goldhammer H. The Fenway Guide to Lesbian, Gay, Bisexual and Transgender Health, 2nd Philadelphia: American College of Physicians. 2015.

10. Lambda Legal. When Healthcare Isn't Caring: Lambda Legal's Survey on Discrimination Against LGBT People and People Living with HIV. New York: Lambda Legal. 2010.

11. Institute of Medicine. The Health of Lesbian, Gay, Bisexual, and Transgender People: Building a Foundation for Better Understanding. Washington, DC: The National Academies Press, 2011, 366 p.

12. Solotke M, Sitkin, NA, Schwartz, ML, Encandela JA. Twelve tips for incorporating and teaching sexual and gender minority health in medical school curricula. Med Teach. 2019 Feb;41(2):141-46.

13. Hafferty FW. Beyond curriculum reform: confronting medicine's hidden curriculum. Acad Med. 1998;73(4):403-407.

14. Maudsley RF. Role models and the learning environment: Essential elements in effective medical education. Acad Med. 2001;76(5):432-434.

15. Fallin-Bennett K. Implicit bias against sexual minorities in medicine: cycles of professional influence and the role of the hidden curriculum. Acad Med. 2015;90(5):549-52.

16. Phelan SM, Burke SE, Hardeman RR, et al. Medical school factors associated with changes in implicit and explicit bias against gay and lesbian people among 3492 graduating medical students. J Gen Intern Med. 2017;32(11):1193-201.

17. Golden, B. Change: Transforming healthcare organizations. Healthc Q. 2016;10:10-19. 
18. Cooper MB, Chacko M, Christner J. Incorporating LGBT health in an undergraduate medical education curriculum through the construct of social determinants of health. MedEdPortal; 2018. Retrieved from https://www.mededportal.org/publication/10781/

19. Safer JD, Pearce EN. (2013). A simple curriculum content change increased medical student comfort with transgender medicine. Endocr Pract. 2013;19:633-7.

20. Thomas DD, Safer JD. (2015). A simple intervention raised resident-physician willingness to assist transgender patients seeking hormone therapy. Endocr Pract. 2015;21(10):1134-42.

21. Erikkson SES, Safer JD. Evidence-based curricular content improves student knowledge and changes attitudes towards transgender medicine. Endocr Pract. 2016;22(7):837-41.

22. Park JA, Safer, JD. Clinical exposure to transgender medicine improves students' preparedness above levels seen with didactic teaching alone: A key addition to the Boston University model for teaching transgender healthcare. Transgend Health. 2018;3(1):10-16.

23. Mehringer J, Bacon E, Cizek S, Kanters A, Fennimore, T. Preparing Future Physicians to Care for LGBT Patients: A Medical School Curriculum. MedEdPORTAL. 2013.

24. Grosz AM, Gutierrez D, Lui AA, Chang, JJ, Cole-Kelley K, Ng H. A student-led introduction to lesbian, gay, bisexual, and transgender health for first-year medical students. Fam Med. 2017;40(1), 52-56.

25. Grubb H, Hutcherson H, Amiel J, Bogart J, Laird J. Cultural Humility with Lesbian, Gay, Bisexual, and Transgender Populations: A Novel Curriculum in LGBT Health for Clinical Medical Students. 2013.

26. Kidd JD, Bockting W, Cabaniss DL, Blumenshine P. Special-“T” training: Extended follow-up results from a residency-wide professionalism workshop on transgender health. Acad Psychiatr. 2016;40:802-6.

27. Bidell MP. Addressing disparities: The impact of a lesbian, gay, bisexual, and transgender graduate counselling course. Couns Psychother Res. 2013;13(4):300-307.

28. Bakhai N, Shields R, Barone M, Sanders R, Fields E. An Active Learning Module Teaching Advanced Communication Skills to Care for Sexual Minority Youth in Clinical Medical Education. MedEdPORTAL, 2016.

29. Johnson K, Rullo J, Faubion S. Student-Initiated Sexual Health Selective as a Curricular Tool. Sex Med. 2015;3(2):118-127.

30. Gacita A, Gargus E, Uchida T, Garcia P, Macken M. Introduction to Safe Space training: Interactive module for promoting a Safe Space learning environment for LGBT medical students. MedEdPortal. 2017.

31. Calzo J, Melchiono M, Richmond TK, Leibowitz SF, Argenol RL. Lesbian, gay, bisexual, and transgender adolescent health: An interprofessional case discussion. 2017.

32. Carabez R, Pellegrini M, Mankovitz A, Eliason MJ, Dariotis WM. Nursing Students' Perceptions of their Knowledge of Lesbian, Gay, Bisexual, and Transgender Issues: Effectiveness of a Multi-Purpose Assignment in a Public Health Nursing Class. J Nurs Educ; Thorofare, 2015;54(1), 50-53. 
33. Taylor AK, Condry H, Cahill D. Implementation of teaching on LGBT health care. Clin Teach, 2017;15:141-44.

34. Ton H, Eidson-Ton WS, losif A, Sitkin N, Henderson S, Callahan E. Using a retreat to develop a 4-year sexual orientation and gender identity curriculum. Acad Psych. 2016;40:796-801.

35. Hernandez R, Nuyen B, Scholz R, Sandhu A, Silva F, Graff N. LGBT Health Immersion Day: Measuring the Impact of an LGBT Health Education Intervention. 2015 APHA Annual Meeting \& Expo.

36.

37. Braun HM, Garcia-Grossman IR, Quinones-Rivera A, Deutsch MB. Outcome and impact evaluation of a transgender health course for health professional students. LGBT Health. 2017;4(1):55-61.

38. Braun HM, Ramirez D, Zahner GJ, Gillis-Buck EM, Sheriff H, Ferrone M. The LGBTQI health forum: an innovative interprofessional initiative to support curriculum reform. Med Educ Online. 2017;22:1306419

39. Vance SR, Deutsch MB, Rosenthal SM, Buckelew SM. Enhancing Pediatric Trainees' and Students' Knowledge in Providing Care to Transgender Youth. The J Adolesc Health: Official Publication of the Society for Adolescent Medicine, 2017;60(4):425-430.

40. Maruca AT, Diaz DA, Stockman C, Gonzalez L. Nurs Educ Perspect. 2018;39(4), 225-29.

41. Yingling CT, Cotler K, Hughes TL. Building nurses' capacity to address health inequities: incorporating lesbian, gay, bisexual and transgender health content in a family nurse practitioner programme. $J$ Clin Nurs. 2017;26, 2807-17.

42. Neff A, Kingery S. Complete Androgen Insensitivity Syndrome: A Problem-Based Learning Case. MedEd PORTAL, 2016.

43. Holthouser A, Sawning S, Leslie KF, et al. eQuality: a process model to develop an integrated, comprehensive medical education curriculum for LGBT, gender nonconforming, and DSD health. Med Sci Educ, 2017;27, 371-383.

44. Leslie KF, Sawning S, Shaw MA, et al. Changes in medical student implicit attitudes following a health equity curricular intervention. Med Teach. 2018;40(4):372-78.

45. Noonan EJ, Sawning S, Combs R, et al. Engaging the transgender community to improve medical education and prioritize healthcare initiatives. Teaching and Learning in Medicine, 2018;30(2):11932.

46. Sawning S, Steinbock S, Croley R, Combs R, Shaw A, Ganzel, T.A. First step in addressing medical education curriculum gaps in gay- lesbian-, bisexual-, and transgender-related content: The University of Louisville LGBT health certificate program. Educ Health, 2017;30(2):108-114.

47. Dowshen $\mathrm{N}$, Matone $\mathrm{M}$, Luan $\mathrm{X}$, et al. Behavioral and health outcomes for HIV+ young transgender women linked to and engaged in medical care. LGBT Health. 2016;3(2):162-7.

48. Yehia BR, Calder D, Flesch JD, et al. Advancing LGBT health at an academic medical center: A case study. LGBT Health, 2015;2(4):362-66. 
49. Gelman A, Amin P, Pletcher J, Fulmer V, Kukic A, Spagnoletti C. A Standardized Patient Case: A Teen Questioning His/Her Sexuality is Bullied at School. MedEdPORTAL, 2014.

50. McNiel PL, Elertson KM. (2017). Advocacy and awareness: Integrating LGBTQ health education into the prelicensure curriculum. Educ Innov. 2017;57(7):312-14.

51. Sullivan W, Eckstrand K, Rush C, Peebles K, Lomis K, Fleming A. An intervention for clinical medical students on LGBTI health. MedEdPORTAL. 2013.

52. Parkhill AM, Mathews JL, Fearing S, Gainsburg J. Instructional design and assessment: A transgender health care panel discussion in a required diversity course. Am J Pharm Educ. 2014;78(4):81.

53. Strong KL, Folse VN. Assessing undergraduate nursing students' knowledge, attitudes, and cultural competence in caring for lesbian, gay, bisexual, and transgender patients. J Nurs Educ. 2015;54(1), 45-49.

\section{Tables}

Table 1. Critical Assessment of SGM Curricular Learning Interventions for Students of Health Professions 


\begin{tabular}{|c|c|c|c|c|}
\hline Institution & $\begin{array}{l}\text { Included } \\
\text { comparison } \\
\text { group? }\end{array}$ & $\begin{array}{l}\text { Use of } \\
\text { validated } \\
\text { scale? }\end{array}$ & $\begin{array}{l}\text { Level of } \\
\text { intervention }\end{array}$ & $\begin{array}{l}\text { Inclusion and exclusion (and unique } \\
\text { considerations) }\end{array}$ \\
\hline $\begin{array}{l}\text { Boonshoft School of Medicine, } \\
\text { Wright State University }{ }^{19}\end{array}$ & No & No & Individual & Included \\
\hline $\begin{array}{l}\text { Boston University School of } \\
\text { Medicine }^{20-23}\end{array}$ & $\mathrm{No}^{20-23}$ & $\mathrm{No}^{20-23}$ & Individual & Included \\
\hline $\begin{array}{l}\text { Case Western University School of } \\
\text { Medicine }^{24,25}\end{array}$ & $\mathrm{No}^{24,25}$ & $\mathrm{No}^{24,25}$ & Individual & Included \\
\hline Columbia University ${ }^{26,27}$ & $\mathrm{No}^{26,27}$ & $\mathrm{No}^{26,27}$ & Individual & $\begin{array}{l}{ }^{26} \text { Excluded: Results not reported } \\
{ }^{27} \text { Included: One of few longitudinal } \\
\text { designs; } 90 \text {-day follow up showed } \\
\text { return to baseline scores }\end{array}$ \\
\hline $\begin{array}{l}\text { Hunter College of the City } \\
\text { University of New York }{ }^{28}\end{array}$ & Yes & Yes & Individual & Included \\
\hline $\begin{array}{l}\text { Johns Hopkins School of } \\
\text { Medicine }^{29}\end{array}$ & No & No & Individual & Included \\
\hline $\begin{array}{l}\text { May Medical School, Rochester, } \\
\mathrm{MN}^{30}\end{array}$ & No & No & Individual & $\begin{array}{l}\text { Included: One of few longitudinal } \\
\text { designs; } 30 \text {-day follow-up showed } \\
\text { retention of knowledge gains } \\
\text { posttest }\end{array}$ \\
\hline $\begin{array}{l}\text { Northwestern University Feinberg } \\
\text { School of Medicine }\end{array}$ & No & No & Individual & Included \\
\hline San Diego State University ${ }^{32}$ & No & No & Individual & Included \\
\hline $\begin{array}{l}\text { School of Nursing, San Francisco } \\
\text { State University }{ }^{33}\end{array}$ & No & $\mathrm{N} / \mathrm{A}$ & N/A & $\begin{array}{l}\text { Excluded: Focus is on practitioners, } \\
\text { not student learning }\end{array}$ \\
\hline $\begin{array}{l}\text { University of Bristol (United } \\
\text { Kingdom) }\end{array}$ & No & No & Individual & Included \\
\hline $\begin{array}{l}\text { University of California Davis } \\
\text { School of Medicine }{ }^{35}\end{array}$ & No & $\mathrm{N} / \mathrm{A}$ & Systems & Included \\
\hline $\begin{array}{l}\text { University of California San Diego } \\
\text { School of Medicine }{ }^{36}\end{array}$ & No & No & Individual & Included \\
\hline $\begin{array}{l}\text { University of California, San } \\
\text { Francisco }^{37}\end{array}$ & No & $\mathrm{N} / \mathrm{A}$ & Individual & $\begin{array}{l}\text { Excluded: No formal assessment } \\
\text { conducted }\end{array}$ \\
\hline $\begin{array}{l}\text { University of California, San } \\
\text { Francisco }^{38-40}\end{array}$ & $\mathrm{No}^{38-40}$ & $\mathrm{No}^{38-40}$ & $\begin{array}{l}\text { Individual }^{38-} \\
39\end{array}$ & Included \\
\hline $\begin{array}{l}\text { University of Connecticut School of } \\
\text { Nursing \& University of Central } \\
\text { Florida College of Nursing }{ }^{41}\end{array}$ & No & Yes & $\begin{array}{l}\text { Individual }^{40} \\
\text { Individual }\end{array}$ & Included \\
\hline $\begin{array}{l}\text { University of Illinois at Chicago, } \\
\text { School of Nursing }\end{array}$ & No & No & Individual & $\begin{array}{l}\text { Excluded. No formal evaluation } \\
\text { conducted. }\end{array}$ \\
\hline University of Louisville, & $\mathrm{No}^{43}$ & $\mathrm{No}^{43}$ & Individual & Included: ${ }^{44,45}$ Describes the \\
\hline Kentucky ${ }^{43-47}$ & $\begin{array}{l}\mathrm{N} / \mathrm{A}^{44} \\
\mathrm{Yes}^{45} \\
\mathrm{~N} / \mathrm{A}^{46} \\
\mathrm{No}^{47}\end{array}$ & $\begin{array}{l}\mathrm{N} / \mathrm{A}^{44} \\
\mathrm{Yes}^{45} \\
\mathrm{~N} / \mathrm{A}^{46} \\
\mathrm{No}^{47}\end{array}$ & and Systems & $\begin{array}{l}\text { innovation and outcomes of the } \\
\text { innovation; }{ }^{43,47} \text { Components of the } \\
\text { larger systems-level work; } \\
{ }^{46} \text { Formative work }\end{array}$ \\
\hline University of Pennsylvania & Yes $^{2}$ & $\mathrm{No}^{2}$ & Individual $^{2}$ & Included \\
\hline $\begin{array}{l}\text { Perelman Schools of Medicine, } \\
\text { Nursing, and Dentistry } 2,48,49\end{array}$ & $\begin{array}{l}\mathrm{No}^{48} \\
\mathrm{~N} / \mathrm{A}^{49}\end{array}$ & $\begin{array}{l}\mathrm{N} / \mathrm{A}^{48} \\
\mathrm{~N} / \mathrm{A}^{49}\end{array}$ & $\begin{array}{l}\text { Systems } \\
\text { Systems } \\
\text { S9 }\end{array}$ & \\
\hline $\begin{array}{l}\text { University of Pittsburg School of } \\
\text { Medicine } 50\end{array}$ & No & No & Individual & Included \\
\hline University of Wisconsin-Oshkosh, & No & No & Individual & Included \\
\hline
\end{tabular}


School of Nursing ${ }^{51}$

Vanderbilt University School of No No Individual Included

Medicine $^{52}$

Wegman's School of Pharmacy, No No Individual Included

Rochester, New York ${ }^{53}$

Wesleyan University ${ }^{54}$

Yale University School of

Medicine $^{12}$

No Yes Individual Included

N/A N/A Systems Excluded: Not a study

Table 2. Lesson Learned During SGM Curricular Implementation Process

\section{Lesson Example quotation}

learned

Do not My bigger question would be, what happens if [name] leaves? What happens, is there somebody who is

rely on going to step into that role if she goes? And I don't know that I see this administrator saying, "Oh I really

one or a need to find somebody to make sure that we continue to"... you need more than a couple of people to

few understand. Because at any given point in any academic career, you're going to have folks who come and

people

Start

I think too would be definitely to find the champions on campus that are doing this work and to support

with them and then try to figure out how to align the work that[is] currently going on with the medical

what you curriculum and build from that so that it doesn't seem like you're starting from scratch. But that you're have

Show the

So I think it's sort of partly about ensuring that the feedback you get is going to be useful in helping necessity you...either improve what you've got, or just kind of demonstrate that there's a need for it. Because if everybody at the beginning said, "We really don't need this," and everybody at the end said, "I'm still, of the I'm still fine. I didn't really learn anything new," then okay, fine, we maybe we would have given up on it. content 
Table 3. Strategies for Curricular Inclusion

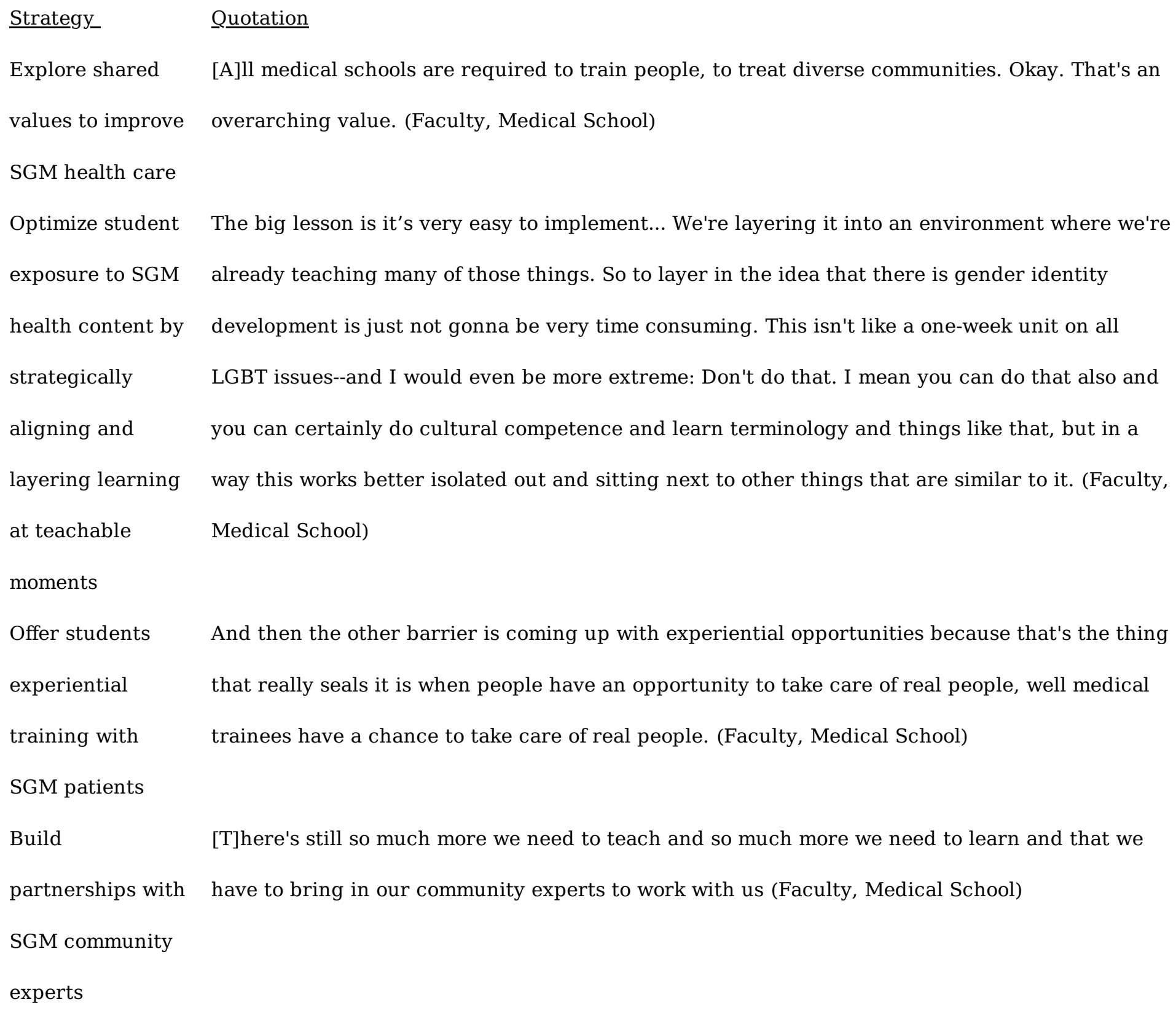

\section{Figures}




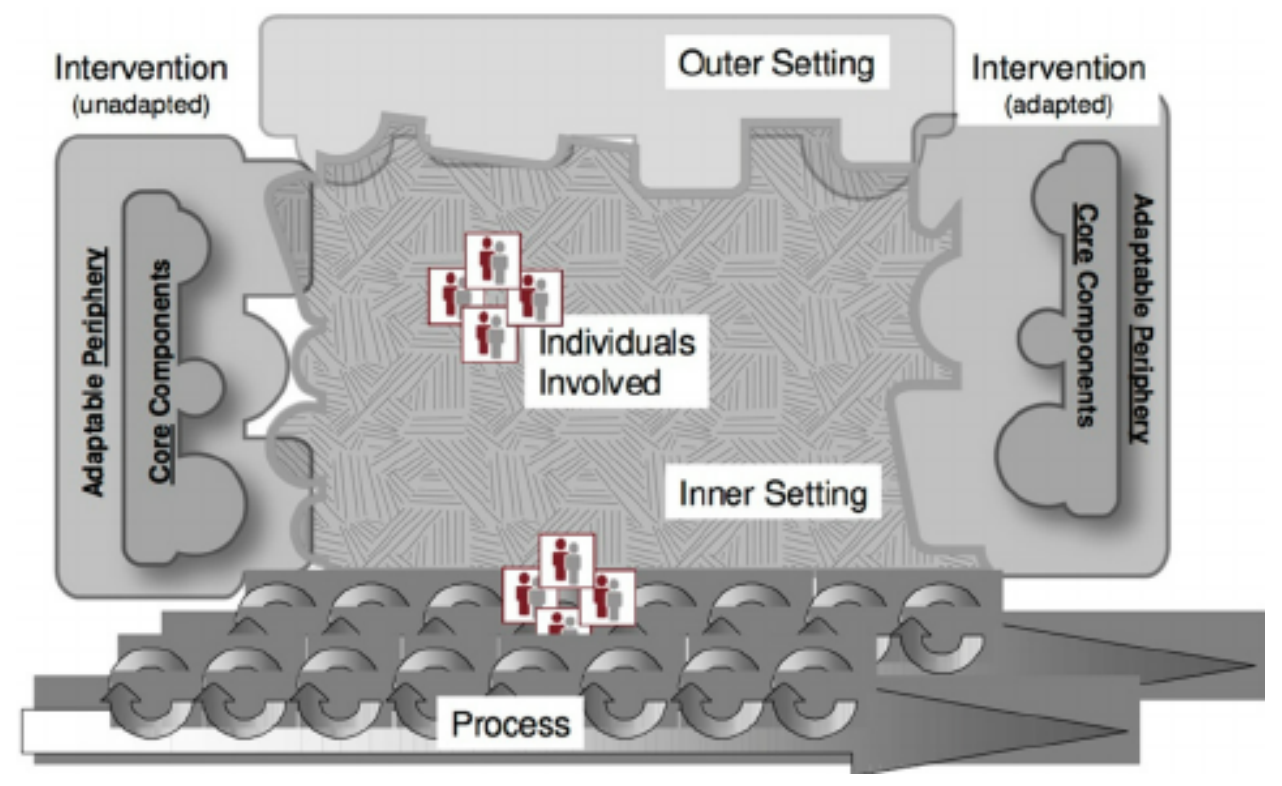

Figure 1

Consolidated Framework for Implementation Research (CFIR)

\section{Supplementary Files}

This is a list of supplementary files associated with this preprint. Click to download.

- SupplementalMaterialsInterviewGuide.docx 